\title{
Why can't I exercise during pregnancy? Time to revisit medical 'absolute' and 'relative' contraindications: systematic review of evidence of harm and a call to action
}

\author{
Victoria L Meah ๑, ${ }^{1}$ Gregory A Davies, ${ }^{2}$ Margie H Davenport ${ }^{1}{ }^{1}$
}

\begin{abstract}
- Additional material is published online only. To view please visit the journal online (http://dx.doi.org/10.1136/ bjsports-2020-102042).

${ }^{1}$ Program for Pregnancy and Postpartum Health, Faculty of Kinesiology, Sport, and Recreation, Women and Children's Health Research Institute, Alberta Diabetes Institute, University of Alberta, Edmonton, Alberta, Canada ${ }^{2}$ Department of Obstetrics and Gynecology, Queen's University, Kingston, Ontario, Canada
\end{abstract}

Correspondence to Dr Margie H Davenport, Faculty of Kinesiology, Sport, and Recreation, University of Alberta, Edmonton, AB T6G 2R3, Canada; mdavenpo@ualberta.ca

Accepted 28 April 2020 Published Online First 8 June 2020

\section{Check for updates}

(C) Author(s) (or their employer(s)) 2020. No commercial re-use. See rights and permissions. Published by BMJ.

To cite: Meah VL, Davies GA, Davenport MH. Br J Sports Med

2020;54:1395-1404.

\section{ABSTRACT}

Background Clinical guidelines recommend pregnant women without contraindication engage in regular physical activity. This is based on extensive evidence demonstrating the safety and benefits of prenatal exercise. However, certain medical conditions or contraindications warrant a reduction, modification or cessation of activity due to potential health risks.

Aim To review and evaluate the evidence related to medical disorders which may warrant contraindication to prenatal exercise.

Methods Online databases were searched up to 5 April 2019. Forty-four unique studies that reported data on our Population (pregnant women with contraindication to exercise), Intervention (subjective/objective measures of acute or chronic exercise), Comparator (not essential) and Outcomes (adverse maternal or fetal outcomes) were included in the review.

Key findings We found that the majority of medical conditions listed as contraindications were based on expert opinion; there is minimal empirical evidence to demonstrate harm of exercise and benefit of activity restriction. We identified 11 complications (eg, gestational hypertension, twin pregnancy) previously classified as contraindications where women may in fact benefit from regular prenatal physical activity with or without modifications. However, the evidence suggests that severe cardiorespiratory disease, placental abruption, vasa previa, uncontrolled type 1 diabetes, intrauterine growth restriction, active preterm labour, severe pre-eclampsia and cervical insufficiency are associated with strong potential for maternal/fetal harm and warrant classification as absolute contraindications. Conclusion Based on empirical evidence, we provide a call to re-evaluate clinical guidelines related to medical disorders that have previously been considered contraindications to prenatal exercise. Removing barriers to physical activity during pregnancy for women with certain medical conditions may in fact be beneficial for maternal-fetal health outcomes.

\section{INTRODUCTION}

Prenatal exercise guidelines around the world recommend that women without contraindication engage in regular physical activity throughout pregnancy. ${ }^{1-14}$ These recommendations are based on an extensive body of literature that supports the safety and benefits of prenatal exercise. We have recently demonstrated that regular exercise during pregnancy was associated with a $\sim 40 \%$ reduction in the odds of developing major pregnancy complications such as pre-eclampsia, gestational hypertension and gestational diabetes, ${ }^{15}$ a reduction in maternal depressive symptoms ${ }^{16}$ and a decreased odds of delivering a macrosomic infant (birth weight $>4000 \mathrm{~g}$ ). ${ }^{17}$ Critically, these benefits occur without increasing the risk of having a small baby, preterm birth or a miscarriage. ${ }^{18}$ Despite these known benefits of physical activity on maternal and fetal health, there remains a subset of women who are advised against exercise due to a variety of preexisting or pregnancy-specific conditions, known as contraindications.

Physical activity is a spectrum of movement behaviours including moderate to vigorous physical activity (MVPA; for example, exercise), light activities (eg, gentle walking and activities of daily living) and sedentary behaviours (eg, sitting/screen time). Traditionally, women who developed contraindications during pregnancy were prescribed a severe form of sedentary behaviour, known as bed-rest. However, data from comprehensive meta-analyses have shown no benefit of bed-rest on pregnancy outcomes ${ }^{1920}$ and an increased risk of preterm birth when prescribed to women in developed countries. ${ }^{21}$ Despite the lack of efficacy and severe health risks of this practice, up to $87 \%$ of physicians in North America still prescribe bed-rest for high-risk pregnant women for lack of a better therapeutic option. ${ }^{223}$ Of particular concern, the majority of physicians prescribing bed-rest to pregnant women do not provide any recommendations of rehabilitative exercise, ${ }^{22}$ which may alleviate some of the negative side effects of activity restriction.

Most guidelines for prenatal exercise include contraindications with various categorisations (table 1); yet for many contraindications, there is no evidence demonstrating that doctors banning exercise in these women improves pregnancy outcomes. Most contraindications are based on expert opinion and may be outdated in light of new empirical evidence on the wide-ranging benefits of prenatal exercise. The aim of this review is to examine the impact of acute and chronic prenatal exercise in women with contraindications to identify potential benefits or risks to maternal/fetal health. Based on available literature, we propose new classifications for absolute and relative contraindications and provide a call to action for inclusion of these women in future research and guidelines, removing barriers to physical activity in these groups of women where appropriate. 
Table 1 Absolute and relative contraindications to prenatal exercise in guidelines from around the world

\begin{tabular}{|c|c|c|c|c|}
\hline Contraindication & SOGC/CSEP ${ }^{1-3}$ & $10 C^{7}$ & $\mathrm{ACOG}^{6}$ & SMA $^{5}$ \\
\hline \multicolumn{5}{|l|}{ Absolute } \\
\hline \multicolumn{5}{|l|}{ Cardiovascular disorders } \\
\hline Serious cardiovascular disorder & $\mathrm{x}$ & Haemodynamically significant & Haemodynamically significant & \\
\hline Chronic hypertension, uncontrolled & $\mathrm{X}$ & $\mathrm{x}$ & & \\
\hline Hypertensive disorders of pregnancy & & & & $\mathrm{x}$ \\
\hline Gestational hypertension & & $\mathrm{x}$ & $\mathrm{x}$ & \\
\hline Pre-eclampsia & $\mathrm{x}$ & $\mathrm{x}$ & $\mathrm{x}$ & \\
\hline \multicolumn{5}{|l|}{ Respiratory disorders } \\
\hline Serious respiratory disorders & $\mathrm{x}$ & & & \\
\hline Restrictive lung disease & & $\mathrm{x}$ & $\mathrm{x}$ & \\
\hline \multicolumn{5}{|l|}{ Pregnancy-specific disorders } \\
\hline IUGR & $\mathrm{X}$ & $\mathrm{x}$ & & Growth-restricted fetus \\
\hline Multiple pregnancies & High order $(\geq 3)$ & Risk of PTL & Risk of PTL & High order $(\geq 3)$ \\
\hline Persistent vaginal bleeding & $\mathrm{X}$ & $\mathrm{T} 2$ or $\mathrm{T} 3$ & $\mathrm{~T} 2$ or $\mathrm{T} 3$ & \\
\hline Placenta previa & After 28 weeks & After 26 weeks & After 26 weeks & After 28 weeks \\
\hline PPROMs & $\mathrm{X}$ & $\mathrm{x}$ & $\mathrm{x}$ & $\mathrm{x}$ \\
\hline Preterm labour (including premature contractions) & $x$ & $\mathrm{x}$ & $x$ & Signs of \\
\hline Cerclage & & $\mathrm{x}$ & $\mathrm{x}$ & \\
\hline Incompetent cervix & $\mathrm{x}$ & & $\mathrm{x}$ & $\mathrm{x}$ \\
\hline Cervical insufficiency & & $\mathrm{x}$ & & \\
\hline \multicolumn{5}{|l|}{ Other disorders } \\
\hline Anaemia (severe) & & $\mathrm{x}$ & $\mathrm{x}$ & \\
\hline Systemic disorder & $x$ & & & \\
\hline Thyroid disease, uncontrolled & $\mathrm{x}$ & & & \\
\hline Type 1 diabetes, poorly controlled & $\mathrm{x}$ & & & \\
\hline \multicolumn{5}{|l|}{ Relative } \\
\hline \multicolumn{5}{|l|}{ Cardiovascular disorders } \\
\hline Cardiac arrhythmia, unevaluated & & $\mathrm{x}$ & $\mathrm{x}$ & \\
\hline Cardiovascular disorders, mild/moderate & $\mathrm{X}$ & & & $\mathrm{x}$ \\
\hline Chronic hypertension, uncontrolled & & & $\mathrm{x}$ & Hypertension (all) \\
\hline Gestational hypertension & $\mathrm{x}$ & & & \\
\hline \multicolumn{5}{|l|}{ Respiratory disorders } \\
\hline Mild/moderate respiratory disorders & $x$ & $\mathrm{x}$ & & $\mathrm{x}$ \\
\hline Chronic bronchitis & & $x$ & $x$ & \\
\hline Smoking, heavy (>20 cigarettes/day) & & & Heavy smoker (all quantities) & \\
\hline \multicolumn{5}{|l|}{ Pregnancy-specific disorders } \\
\hline IUGR & & History of & $x$ & In current pregnancy \\
\hline History of premature birth & $x$ & $x$ & & $x$ \\
\hline Recurrent pregnancy loss & $\mathrm{x}$ & History of & & \\
\hline Previous spontaneous abortion & & History of & & $x$ \\
\hline Twin pregnancies $>28$ weeks & $\mathrm{x}$ & & & $\mathrm{x}$ \\
\hline Cervical enlargement & & $x$ & & \\
\hline \multicolumn{5}{|l|}{ Other disorders } \\
\hline Epilepsy, poorly controlled & & Seizure disorder & Seizure disorder & \\
\hline Thyroid disease, uncontrolled & & & Hyperthyroidism & Hyperthyroidism \\
\hline Type 1 diabetes, poorly controlled & & $x$ & $x$ & $x$ \\
\hline Orthopaedic limitations & & $\mathrm{x}$ & $\mathrm{x}$ & \\
\hline Other significant medical conditions & $x$ & & & $x$ \\
\hline Anaemia & Symptomatic & & $x$ & $\mathrm{Hb}<100 \mathrm{~g} / \mathrm{L}$ \\
\hline Eating disorder & $x$ & Extreme underweight & $\mathrm{BMI}<12 \mathrm{~kg} / \mathrm{m}^{2}$ & $x$ \\
\hline Malnutrition & $x$ & Extreme underweight & $\mathrm{BMI}<12 \mathrm{~kg} / \mathrm{m}^{2}$ & $x$ \\
\hline Obesity & & & $\mathrm{BMI}>40 \mathrm{~kg} / \mathrm{m}^{2}$ & $\mathrm{BMI}>30 \mathrm{~kg} / \mathrm{m}^{2}$ \\
\hline History of extremely sedentary lifestyle & & & $x$ & \\
\hline
\end{tabular}

Adapted from Evenson et al (2014). ${ }^{135}$

Guidance from the UK Chief Medical Officer states that exercise should be recommended to women with uncomplicated pregnancies. ${ }^{4}$ However, women with obstetric or medical complications may perform moderate intensity physical activity during pregnancy but should receive additional monitoring and/or specialist support. ${ }^{136}$

ACOG, American College of Obstetricians and Gynecologists; BMI, body mass index; CSEP, Canadian Society for Exercise Physiology; Hb, haemoglobin; IUGR, intrauterine growth restriction;

PPROMs, preterm premature rupture of membrane; PTL, preterm labour; SMA, Sports Medicine Australia; SOGC, Society of Obstetricians and Gynaecologists of Canada; T2, second trimester;

T3, third trimester. 
We systematically searched the literature for studies on physical activity in women with contraindications (see online supplementary material for search strategy) and provide evidence to support or refute the inclusion of these conditions as relative or absolute contraindications in future guidelines. Absolute contraindications are medical conditions in which women are discouraged from engaging in any MVPA, whereas relative contraindications warrant discussion between the pregnant woman and her obstetric healthcare professional about potential risks and benefits of prenatal exercise. Additionally, we considered each contraindication in relation to risks of adverse maternal and neonatal health outcomes (online supplementary table 1). Our recommendations are summarised below, with detailed supplementary information supporting each recommendation in the online supplementary material.

\section{METHODS}

Detailed methods are included in the online supplementary material. The PICOS (Population, Intervention, Comparison, Outcome and Study design) framework was used to guide this review. ${ }^{24}$ The population of interest was pregnant women with absolute or relative contraindications to exercise as defined by previous guidelines (table 1). The intervention/exposure of interest was subjective or objective measures of frequency, intensity, duration, volume or type of prenatal exercise. Acute (ie, a single exercise session) or habitual (ie, usual activity) prenatal exercise was considered. No comparators were required for inclusion in this review and relevant outcomes were any reports related to maternal/neonatal morbidity or mortality. Primary studies of any design were eligible, including case studies. A comprehensive search was created and run (see online supplementary material for complete search strategies) and study screening and selection were managed using Covidence systematic review software (Veritas Health Innovation, Melbourne, Australia).

\section{RESULTS}

Overall, 44 unique studies were included in the review (online supplementary figure 1). Additional details about the studies can be found in the online supplementary table 2. A narrative synthesis of results is presented for each contraindication with more details included in the online supplement.

\section{Absolute contraindications}

Women with absolute contraindications are discouraged from engaging in MVPA; however, activities of daily living should be continued. We identified the following conditions where engaging in regular MVPA has a strong potential for adverse effects for the mother and/or fetus:

- Severe respiratory diseases (eg, chronic obstructive pulmonary disease, restrictive lung disease and cystic fibrosis).

- Severe acquired or congenital heart disease with exercise intolerance.

- Uncontrolled or severe arrhythmia.

- Placental abruption.

- Vasa previa.

- Uncontrolled type 1 diabetes.

- Intrauterine growth restriction (IUGR).

- Active preterm labour.

- Severe pre-eclampsia.

- Cervical insufficiency.

\section{Severe respiratory disorders}

Individuals with respiratory disorders, including chronic obstructive pulmonary disease, restrictive lung disease, cystic fibrosis and asthma, experience symptoms of dyspnoea, chronic coughing and chest tightness that can be worsened with exertion. The severity of the disease is quantified using a range of diagnostic criteria that considers symptoms, pathophysiology and how advanced the disorder is.

There is a paucity of data regarding the benefits and risks of prenatal physical activity in women with mild-moderate or severe respiratory disorders. In a series of case reports of pregnant women with severe restrictive lung disease, low-intensity walking exercise led to a fall in oxygen saturation of $5 \%-50 \%{ }^{25}$ Reduced maternal arterial oxygen content as a result of prenatal exercise may decrease oxygen delivery to the fetoplacental unit and elevate the risk for fetal hypoxia. Given this significant risk to fetal well-being, we believe severe respiratory disorders should remain an absolute contraindication to prenatal exercise. Future experimental research is required to examine whether different modalities of exercise that do not exacerbate symptoms, such as resistance training or yoga, may be safe alternatives for these populations. During such studies, maternal oxygen saturation and fetal well-being should be monitored and appropriate safety measures (eg, supplemental oxygen, walkers, pharmacological interventions like bronchodilators) are strongly recommended.

Women with mild-moderate respiratory disorders prior to pregnancy have more favourable pregnancy outcomes than those with severe disease. ${ }^{26}$ As such, these women face less risk and greater health benefits of prenatal physical activity. In general, pregnant women with well-controlled (ie, regular use of bronchodilators and inhaled corticosteroids) mild-moderate respiratory disorders tolerate prenatal exercise well. In fact, one study including pregnant women with bronchitis found that regular supervised exercise reduced the incidence of respiratory illness (either new onset or exacerbations) when compared with no exercise. ${ }^{27}$ In light of these potential benefits and limited risk of harm, women with well-controlled, mild-moderate respiratory diseases who are asymptomatic should be encouraged to maintain MVPA during pregnancy without any restriction. Women with mild-moderate respiratory disease who experience exacerbations or symptoms of exercise intolerance (undue shortness of breath) should reduce the intensity of exercise, but remain physically active (see table 2 ).

\section{Severe congenital or acquired heart disease}

Heart disease (HD) is a term used to encompass a variety of congenital and acquired cardiac disorders including, but not limited to, stenotic or regurgitant valvular lesions, repaired or unrepaired septal defects, operated coarctation of the aorta, healed myocarditis and arrhythmia. Patients with HD are categorised according to their symptoms using the New York Heart Association (NYHA) functional classification system (Class I-no limitation of physical activity to Class IV-symptoms of dyspnoea and/or chest pain at rest). ${ }^{28}$ Patients with HD are encouraged to engage in regular MVPA to improve health and well-being ${ }^{29}$; however, these recommendations do not specifically cover pregnant women with HD.

Pregnant women with congenital or acquired HD with exercise tolerance (ie, NYHA functional class I to II) have markedly reduced cardiac responses to exercise compared with pregnant women without HD. ${ }^{30} 31$ However, women with NYHA functional class I or II HD are able to exercise beneath their threshold of exacerbated symptoms and can receive many health 
Table 2 Specific classifications of pre-existing contraindications to prenatal physical activity

\begin{tabular}{ll}
\hline Absolute contraindication & Relative contraindication \\
\hline Avoid MVPA, but maintain activities of daily living & $\begin{array}{l}\text { Could be recommended MVPA, with } \\
\text { or without modifications, and should } \\
\text { maintain activities of daily living }\end{array}$ \\
& Potential modifications
\end{tabular}

\section{Respiratory disorders}

\begin{tabular}{|c|c|}
\hline COPD & $\begin{array}{l}\text { Severe: } \\
\text { GOLD } 3 \text { or } 4\end{array}$ \\
\hline Asthma & $\begin{array}{l}\text { Severe: } \\
\mathrm{FEV}_{1}<60 \% \text {, daily oral corticosteroid use } \\
\text { Symptomatic }\end{array}$ \\
\hline Cystic fibrosis & $\begin{array}{l}\text { Severe: } \\
\mathrm{FEV}_{1}<50 \% \\
\text { Clinically unstable } \\
\text { Worsening disease status } \\
\text { Presence of Burkholderia cepacia or MRSA }\end{array}$ \\
\hline Restrictive lung disease & $\begin{array}{l}\text { Severe: } \\
\mathrm{FEV}_{1}<60 \%\end{array}$ \\
\hline
\end{tabular}

\begin{tabular}{|c|c|}
\hline Type 1 diabetes & $\begin{array}{l}\text { Uncontrolled: } \\
\text { Unpredictable or frequent hypoglycaemia } \\
\text { Presence of comorbidities: Uteroplacental insufficiency } \\
\text { Fetal growth restriction } \\
\text { Hypertensive disorders } \\
\text { Chronic renal disease }\end{array}$ \\
\hline Congenital heart disease & $\begin{array}{l}\text { Severe: } \\
\text { NYHA functional class III or IV }\end{array}$ \\
\hline Arrhythmia & $\begin{array}{l}\text { Symptomatic or severe: } \\
\text { Symptoms including (pre)syncope, onset of ventricular } \\
\text { premature beats, exertional fatigue } \\
\text { Severe conditions, for example, ventricular tachycardia, } \\
\text { implantable defibrillators } \\
\text { Contraindicated from exercise prior to pregnancy }\end{array}$ \\
\hline
\end{tabular}
Smoking Eating disorders

\section{Moderate-heavy ( $\geq 20$ cigarettes per day)} with comorbidities:

IUGR

Hypertensive disorders

\section{Symptomatic:}

Inadequate GWG

Exhibiting restrictive or compensatory

behaviours

Reduced fetal growth
Remain physically active below threshold of intolerance

Remain physically active below threshold of intolerance

Remain physically active below threshold of intolerance

Remain physically active below threshold of intolerance

Use of continuous glucose monitor and/or insulin pump to improve glycaemic control. Educated about precautionary measures to avoid postexercise and nocturnal hypoglycaemia

Exercise below threshold of intolerance

Low-moderate intensity activity benefits from doing so. These women should remain physically active within their tolerance levels, but taper exercise intensity (if needed) as pregnancy progresses. ${ }^{3031}$ In contrast, women with more severe forms of HD (ie, NYHA class III to IV) have diminished exercise capacity and exercise intolerance in their nonpregnant state. In the rare cases of pregnancy in women with NYHA functional class III to IV HD, exercise intolerance is more severe (eg, oxygen desaturation, syncope, reduced uteroplacental blood flow, worsening of symptoms and/or symptomatic arrhythmia) and associated with greater risks. ${ }^{30} 32$ Women with severe HD should therefore avoid prenatal exercise but should continue activities of daily living.

Exercise tolerance of women with HD may be determined through cardiopulmonary exercise testing completed prior to or early during pregnancy. The results from this test could be used to oppose or recommend prenatal physical activity in these women. However, for those women who tolerate physical activity well (NYHA I or II), an exercise test may not be medically indicated, but if conducted the results of could also be used to prescribe exercise. Additionally, the results from exercise testing in women with HD have some predictive value regarding pregnancy outcomes, ${ }^{33} 34$ and as such, ${ }^{35}$ American College of Obstetricians and Gynecologists and the Task Force on the Management of Cardiovascular Diseases during Pregnancy recommends this practice. ${ }^{36}$

Non-pregnant individuals with arrhythmias face greater risks during physical activity as a result of exercise-induced changes in autonomic tone, which could lead to ventricular arrhythmias. ${ }^{29}$ Individuals with severe or uncontrolled arrhythmias are encouraged to participate in activities with low cardiovascular demand (ie, low intensity). ${ }^{37} 38$ The majority of pregnant women with arrhythmias are treated and well-controlled, and especially if exercising prior to pregnancy should be supported to engage in MVPA. In contrast, women with untreated, symptomatic or severe arrhythmias and who were contraindicated from exercise prior to pregnancy should not participate in prenatal exercise but maintain activities of daily living (see table 2 ).

\section{Placental abruption}

Placental abruption describes the partial or complete separation of the implanted placenta from the uterus that results in maternal bleeding and/or pain. Larger placental abruptions can cause uteroplacental insufficiency, ischaemia, chronic hypoxaemia 
and/or fetal death. ${ }^{39}$ When placental abruption is diagnosed during pregnancy, women should stop MVPA due to the high risks to both maternal and neonatal health. ${ }^{40}$

Strenuous physical exercise has previously been suggested to increase the risk of placental abruption. The immediate risk of placental abruption was 7.8-fold higher in the hour following MVPA compared with periods of lower activity or rest, and this was greater following heavy intensity exercise. ${ }^{41}$ However, in this cohort of 663 women, only $54 \%$ of the total population engaged in any MVPA in the week preceding placental abruption, and consequently, it is not clear as to whether avoiding exercise would only delay (not prevent) the inevitable outcome of placental abruption. ${ }^{4142}$ To the contrary, the risk of placental abruption is lower among women who are habitually active compared with those who are sedentary. ${ }^{41}$ Women who have risk factors that are associated with placental abruption should be encouraged to maintain MVPA throughout gestation.

\section{Vasa previa}

Vasa previa describes a complication in which a fetal blood vessel, unprotected by the umbilical cord or placenta, runs through the amniotic membranes and traverses the cervix. ${ }^{434}$ Unrecognised, vasa previa is associated with significant risks of stillbirth as fetal haemorrhage can occur rapidly should membranes rupture prematurely. Women diagnosed with vasa previa during pregnancy are managed through activity restriction and/or hospitalisation to allow close surveillance for signs of labour. The potential risks of vasa previa to fetal health drastically outweigh any benefits of MVPA, and therefore women should be prevented from engaging with prenatal exercise.

\section{Uncontrolled type 1 diabetes mellitus}

Women with type 1 diabetes who have poorly controlled blood glucose levels prior to and during pregnancy are at greater risk of adverse maternal and fetal outcomes when compared with women with well-controlled type 1 diabetes. ${ }^{45}$ In non-pregnant individuals diagnosed with type 1 diabetes, physical activity is encouraged to aid glycaemic control and improve overall health and well-being. ${ }^{46}$ As such, prenatal exercise could improve glycaemic control in pregnant women with type 1 diabetes and lead to more favourable pregnancy outcomes.

Previous reports of prenatal physical activity in pregnant women with type 1 diabetes provide somewhat conflicting evidence of health benefits. Critically, the risk of daytime and nocturnal hypoglycaemia appears to be low following exercise in women with well-controlled blood glucose. ${ }^{47}{ }^{48}$ Pregnant women with well-controlled type 1 diabetes can engage with current MVPA recommendations, but additional measures to mitigate risk should be used. Women should consider the use of a continuous glucose monitor and/or an insulin pump to improve monitoring and control of blood glucose, and women should be well-informed of measures that can reduce the risk of postexercise and nocturnal hypoglycaemia. ${ }^{46}$ In contrast, pregnant women with type 1 diabetes who have unpredictable or frequent hypoglycaemia and/or have comorbidities (such as uteroplacental insufficiency, hypertension or chronic renal disease) should complete activities of daily living, but avoid prenatal exercise (see table 2).

\section{Intrauterine growth restriction}

Impaired fetal growth is a marker of poor placenta function and hypoxaemia. While prenatal exercise does not increase the risk of IUGR, maternal exercise could have negative impacts on fetal well-being in a pregnancy complicated with uteroplacental insufficiency. In women diagnosed with IUGR, prenatal exercise may lead to reduced blood flow to the fetoplacental unit and fetal hypoxia, further raising the risk of adverse outcomes in this population. However, recommending that women with IUGR restrict all physical activity (ie, bed-rest) is not beneficial to fetal growth or pregnancy outcomes. ${ }^{49}$

At present, there are some data demonstrating the acute effects of prenatal exercise in women with IUGR. Previous studies have shown transient increases in umbilical artery pulsatility index, fetal bradycardia and absent end-diastolic flow in the umbilical artery immediately following exercise in women with IUGR (less than 10th percentile estimated fetal weight); however, these deficits recovered within 20-30 s after stopping exercise. ${ }^{5051}$ Another study did not identify differences in fetoplacental outcomes following exercise in women with IUGR (estimated fetal weight 1.5 SD below mean weight). ${ }^{52}$ In contrast, exercise in women with IUGR (less than fifth percentile estimated fetal weight) increased umbilical artery resistance and negatively impacted indices of fetal well-being (increased fetal aortic and cerebral artery resistance index). ${ }^{53}$ These adverse responses to exercise, although transient, may predict those fetuses who consequently develop more severe pathophysiology. ${ }^{54}$

The prevailing literature, although limited, indicates that acute exercise in women with IUGR results in decreased fetal well-being. The risks of MVPA therefore outweigh the benefits in this population, and women with IUGR should be encouraged to avoid exercise, but to maintain activities of daily living.

\section{Active preterm labour}

Preterm birth, defined as delivery before 37 weeks of pregnancy, may be the result of spontaneous labour, premature rupture of membranes or induced labour/delivery due to concerns for maternal or fetal health. ${ }^{55}$ Prenatal exercise is not recommended for women who are in active preterm labour.

Many women, especially in the third trimester, experience uterine activity (Braxton-Hicks contractions), which may become more intense or frequent with MVPA. ${ }^{56-58}$ In contrast to preterm labour, Braxton-Hicks contractions subside with rest, are irregular in their timing and are generally uncomfortable but not painful. Pregnant women who experience regular and painful uterine contractions should cease exercise and seek advice from a healthcare provider. ${ }^{1-3}$

\section{Severe pre-eclampsia}

Pre-eclampsia is the development of hypertension with proteinuria, maternal organ dysfunction and/or uteroplacental dysfunction. ${ }^{5960}$ Pre-eclampsia has more significant consequences to maternal and fetal health when diagnosed at an earlier gestational age and/or with increasing symptoms such as abnormal liver enzymes or thrombocytopaenia. ${ }^{60}{ }^{61}$ Women with severe pre-eclampsia, eclampsia or HELLP (haemolysis, elevated liver enzymes, low platelet count) syndrome require immediate delivery and should not engage in strenuous physical activity, whereas women with milder forms of the disease may be managed until delivery is indicated. The Canadian Hypertensive Disorders of Pregnancy Working Group has stated that strict bed-rest in women who are hospitalised with pre-eclampsia is not recommended. ${ }^{62}$ This shift in management of mild preeclampsia necessitates us to consider the effects of physical activity in these women.

Previous research has shown that acute prenatal exercise in women diagnosed with mild pre-eclampsia did not cause 
adverse changes in blood pressure, uterine contractions, vaginal bleeding, ${ }^{63}$ uterine blood flow or fetal heart rate, ${ }^{6465}$ and in fact reduced diastolic blood pressure postexercise. ${ }^{66}$ However, in women with both pre-eclampsia and IUGR (ie, severe preeclampsia), transient adverse responses to prenatal exercise, such as a reduction in placental blood flow were observed. ${ }^{64} 65$

The accumulating evidence shows that prenatal exercise in women with mild pre-eclampsia offers maternal and fetal health benefits, without increased risk of harm, assuming there has been normal fetal growth. Mild pre-eclampsia should therefore be downgraded to a relative contraindication to exercise, and, in line with the Canadian Hypertensive Disorders of Pregnancy Working Group recommendations, bed-rest or activity restriction should be avoided in these women. Women with mild pre-eclampsia (without concurrent conditions that are absolute contraindications to prenatal exercise) should be encouraged to maintain light physical activity (such as walking, bodyweight exercises or stretching) within current recommendations. In line with previous prenatal physical activity guidelines, women with severe pre-eclampsia should avoid MVPA, but maintain activities of daily living prior to their likely imminent delivery.

\section{Cervical insufficiency}

Cervical insufficiency describes a structural and functional deficit of the cervix that is typically characterised by premature, painless cervical dilation occurring alongside one or more midsecond trimester pregnancy losses without evidence of preterm labour, chorioamnionitis or fetal chromosomal abnormalities. ${ }^{67}$ Cervical dilation can lead to pre-viable delivery and as such, presents significant risks to fetal health. Women with cervical insufficiency should be advised to maintain activities of daily living, and potentially, to complete light upper-body resistance exercise, but avoid MVPA. These recommendations also apply to women with a prophylactic or rescue cervical cerclage in place.

\section{Relative contraindications}

Relative contraindications are conditions that warrant discussion between a pregnant woman and her obstetric healthcare professional about the potential risks and benefits of exercising during pregnancy. Our systematic review identified a number of conditions where this discussion is encouraged. Based on available evidence, we recommend modification of activities (reduction in intensity, duration or volume; exercise adaptation) be considered over an order that the woman should avoid exercise completely. It is our opinion that the following 10 conditions should be considered as relative contraindications to prenatal exercise:

- Mild respiratory disorders (discussed previously).

- Mild congenital or acquired HD (discussed previously).

- Well-controlled type 1 diabetes (discussed previously).

- Mild pre-eclampsia (discussed previously).

- Preterm premature rupture of membranes (PPROMs).

- Placenta previa after 28 weeks.

- Untreated thyroid disease.

- Symptomatic, severe eating disorder.

- Multiple nutrient deficiencies and/or chronic undernutrition.

- Moderate-heavy smoking (>20 cigarettes per day) in the presence of comorbidities.

\section{Preterm premature rupture of membranes}

PPROMs, defined as spontaneous rupture of the membranes before 37 weeks' gestation, occurs in 3\% of all pregnancies. ${ }^{5568}$ Women who experience PPROMs are typically admitted to hospital to undergo expectant management, ${ }^{69}$ as the majority of women will deliver within 7 days following rupture. Previously, women were recommended to restrict physical activity on the basis that it might promote amniotic fluid accrual and thereby prolong latency. ${ }^{68}$ However, a randomised controlled trial of physical activity compared with bed-rest in pregnant women with PPROMs found no differences in amniotic fluid index, latency or maternal and neonatal outcomes between groups. ${ }^{68}$ Further, an observational study of women with confirmed PPROMs demonstrated a significantly longer latency in women with low-intensity physical activity (walking; $\geq 500$ steps per day) compared with those with lower activity $(<500$ steps per day). Again, no adverse maternal or fetal outcomes were identified with increasing activity levels. ${ }^{70}$ It is therefore our recommendation that women diagnosed with PPROMs may engage in low-intensity physical activity and maintain activities of daily living until delivery (after full clinical evaluation and without other absolute contraindications).

\section{Placenta previa after 28 weeks' gestation}

Placenta previa is diagnosed in the third trimester when the placenta overlies the internal cervical os. Placenta previa is common in the first half of pregnancy (identified in $42.3 \%$ of women at 11-14 weeks and $3.9 \%$ of women at $20-24$ weeks) ${ }^{71}$ and commonly resolves by 28 weeks; however, $0.4 \%$ of all pregnancies are diagnosed with placenta previa in the third trimester.

Placenta previa presents significant risks to both maternal and fetal health through uncontrolled vaginal bleeding. ${ }^{72}$ However, not all women with placenta previa experience vaginal bleeding, and those women should continue to participate in MVPA until 28 weeks' gestation. At this gestational age, women should be re-evaluated for the presence of placenta previa. If the placenta previa is resolved, women should continue to exercise within current guidelines. However, women diagnosed with placenta previa after 28 weeks' gestation are at risk for spontaneous labour and should avoid MVPA. However, these women should maintain their activities of daily living and low-intensity activity (ie, walking).

\section{Untreated thyroid disease}

Untreated thyroid disease is associated with symptoms such as chronic fatigue, exercise intolerance, muscle dysfunction and impairments in heart rate kinetics. ${ }^{73}{ }^{74}$ Individuals with untreated hyperthyroidism may experience tachycardia and an elevated myocardial workload at rest, whereas individuals with untreated hypothyroidism will have bradycardia and diminished cardiac responsiveness. As such, untreated thyroid disease leads to impaired maternal cardiac and metabolic function that could reduce oxygen and nutrient delivery to the fetoplacental unit. Pregnant women with untreated thyroid disease should refrain from MVPA until symptoms are rectified with appropriate clinical management. These risks are not apparent for women with treated thyroid disease, and as such, these women should maintain MVPA and activities of daily living without special precautions.

\section{Eating disorders}

Severe cases of anorexia nervosa and/or bulimia nervosa have the potential to lead to caloric and nutrient deficiencies in utero that impair fetal, infant and child development. ${ }^{75} 76$ The majority of women with current eating disorders are able to reduce their restrictive or compensatory eating behaviours during pregnancy. 
Although perinatal complications in this population remain, the relative risk compared with the general population is low. ${ }^{77}$

Prenatal physical activity, in moderation, may offer general health benefits for women with asymptomatic eating disorders, providing that no relapse occurs during gestation. Recent metaanalyses have shown that regular prenatal physical activity in otherwise healthy women reduces the severity of prenatal depressive symptoms and the odds of prenatal depression by $67 \%{ }^{16}$ Therefore, maintaining regular prenatal activity may alleviate or manage psychological factors that may trigger symptoms of an eating disorder. Women with asymptomatic eating disorders (appropriate gestational weight gain (GWG), no restrictive or compensatory behaviours and appropriate fetal growth) should therefore be encouraged to engage in prenatal physical activity within current recommendations.

In rare cases of women with severe symptomatic eating disorders, as indicated by fetal growth restriction, inadequate GWG and restrictive/compensatory behaviours, MVPA should be closely monitored across gestation. Extreme symptoms, such as excessive exercise to control weight and/or to counter binge eating, could result in further caloric restriction and thus negatively impact fetal development. ${ }^{7879}$ Pregnant women with symptomatic eating disorders should avoid MVPA but could engage in low-intensity activity up to duration detailed in current guidelines provided they have regular monitoring from their healthcare provider (see table 2 ).

\section{Undernutrition}

In previous guidelines, 'malnutrition' was considered a relative contraindication to prenatal exercise; however, this is an umbrella term that encompasses overnutrition, undernutrition and nutrient deficiencies. There is significant evidence demonstrating the safety and efficacy of prenatal exercise in women with overnutrition (those categorised as overweight and obese), as well as in women with isolated nutrient deficiencies (eg, anaemia). Therefore, we recommend that undernutrition should be considered a relative contraindication to prenatal exercise but not 'malnutrition'.

Women suffering from multiple nutrient deficiencies or chronic undernutrition are at higher risk for complications and therefore require nutritional intervention. ${ }^{80}$ In situations where undernourished women (without other health complications) are able to make dietary adjustments or take supplements to receive adequate nutrients, prenatal physical activity should be encouraged. However, in reality, improving nutritional status for undernourished women may not be possible without external support and improvements in food access and availability.

\section{Smoking}

One of the most prominent negative effects of maternal smoking is fetal growth restriction. ${ }^{81}{ }^{82}$ Maternal cigarette smoking results in increased fetal carboxyhaemoglobin which reduces oxygen transport and delivery to fetoplacental tissues that can cause chronic carbon monoxide poisoning. ${ }^{83}$ Simultaneously, nicotine-induced vasoconstriction reduces uteroplacental blood flow. ${ }^{84}$ Together, these can lead to fetal hypoxia that will result in delayed short-term and long-term growth and development. ${ }^{85-87}$ Smoking at any point during pregnancy decreases birth weight by approximately $10-12 \mathrm{~g}$ per cigarette/day ${ }^{81}$ with the greatest impact in the third trimester $(27 \mathrm{~g}$ reduction in birth weight for every cigarette smoked per day). ${ }^{82}$

Although prenatal exercise has many benefits to both vascular and placental function in otherwise healthy women, ${ }^{88} 89$ these benefits may be offset by the negative effects of maternal smoking, especially in women with complications such as IUGR. Previous cohort data demonstrated that women who smoked and exercised during pregnancy had a $30 \%$ greater risk of fetal death compared with non-smoking women who did not exercise $(87930$ women, adjusted HR: $1.3,95 \%$ CI: 1.03 to 1.65); however, this analyses was not adjusted for other factors that increase the risk of fetal death such as birth weight and other comorbidities. ${ }^{90}$ Additionally, there was no statistical interaction between prenatal exercise and smoking and risk of fetal death on the additive risk scale. Therefore, we interpret that prenatal exercise in currently smoking pregnant women may provide health benefits to some, but may have negative effects in others; particularly those with other comorbidities including those with IUGR. In light of this, we recommend that pregnant women who are heavy smokers ( $>20$ cigarettes per day) who have other comorbidities who wish to participate in MVPA require close observation to ensure appropriate fetal growth (see table 2).

\section{CONSIDERATIONS FOR PHYSICAL ACTIVITY IN RELATIVE CONTRAINDICATIONS}

To inform the Society of Obstetricians and Gynaecologists of Canada/Canadian Society for Exercise Physiology 2019 Guideline for Physical Activity throughout Pregnancy, 12 systematic reviews were developed and published in two dedicated issues of the British Journal of Sports Medicine. ${ }^{15-1891-98}$ To provide evidencebased support for the recommendations regarding MVPA, metaregression analyses were conducted for critical outcomes with at least 10 randomised controlled trials comparing exercise (without cointerventions) to no exercise. ${ }^{99} 99$ To reduce the odds of gestational diabetes, pre-eclampsia, gestational hypertension, prenatal depressive symptoms and excessive GWG by more than $25 \%$ (or effect size $>0.4$ ), women should aim to achieve $150 \mathrm{~min}$ of MVPA spread over $\geq 3$ days of the week. However, substantial benefits were also observed at volumes below these recommendations; data from non-pregnant populations support that engaging in some physical activity is better than none. ${ }^{100}$ In light of the potential benefits, even at activity levels below current guidelines, it is essential that the frequency, intensity, duration and/or volume of exercise should be modified for women with relative contraindications, rather than preventing activity altogether.

\section{Not a contraindication}

Based on available literature, the following conditions (in isolation) should no longer be considered a barrier to being physically active during pregnancy. These conditions include:

- Chronic hypertension.

- Gestational hypertension.

- Women who are categorised as overweight or obese.

- Recurrent miscarriage.

- Short cervix.

- Twin and high-order pregnancies.

- Epilepsy.

- Anaemia.

- Orthopaedic limitations.*

- History of extremely sedentary lifestyle.*

- History of spontaneous preterm labour or fetal growth restriction.*

* More information about each of these factors can be found in the online supplementary material.

\section{Chronic hypertension}

Chronic hypertension is associated with significant risks for both maternal and fetal morbidity. ${ }^{101-104}$ The front-line therapies to 
treat hypertension are antihypertensive drugs. ${ }^{101}$ Despite the benefit to maternal blood pressure control, these medications do not reduce the risk of fetal growth restriction, pre-eclampsia or preterm delivery. ${ }^{105}$ As such, there is a need for adjunctive therapies to manage pregnancies complicated by chronic hypertension.

Exercise is not a contraindication for women who have controlled chronic hypertension during pregnancy. ${ }^{1-3} \quad 5 \quad 6$ Although the impact of exercise in pregnant women with uncontrolled hypertension has not been examined, we can draw information from non-pregnant hypertensive populations for support. In conjunction with antihypertensive drug treatments, acute bouts of physical activity result in a transient increase in blood pressure that is followed by a sustained decrease in blood pressure. The postexercise decrease of approximately 10 and $7 \mathrm{~mm} \mathrm{Hg}$ in systolic and diastolic blood pressure, respectively, lasts for up to 2 hours following the end of exercise ${ }^{106}$ and can be achieved following as little as $10 \mathrm{~min}$ of moderate intensity aerobic exercise. ${ }^{107}$ This postexercise reduction in blood pressure may therefore reduce the time in which pregnant women with chronic hypertension are exposed to higher-than-average blood pressures during the day. Furthermore, there is a doseresponse relationship between exercise volume and postexercise blood pressure reduction, demonstrating that greater levels of exercise will result in greater lowering of blood pressure over a longer period of time. ${ }^{106}$

In pregnant women with chronic hypertension, no adverse changes in maternal blood pressure, fetal heart rate, uterine artery or umbilical artery blood flow have been observed following acute moderate-intensity exercise. ${ }^{108}$ Additionally, regular prenatal physical activity throughout pregnancy in women with chronic hypertension did not increase the odds of complications such as low birth weight, pre-eclampsia or preterm birth. ${ }^{109}$

The prevailing literature provides evidence that women with chronic hypertension benefit from prenatal physical activity (in conjunction with antihypertensive treatment) without increased risks of adverse maternal or neonatal outcomes. However, pregnant women with uncontrolled hypertension (persistent systolic $\geq 140 \mathrm{~mm} \mathrm{Hg}$ and/or diastolic $\geq 90 \mathrm{~mm} \mathrm{Hg}$ ) should be evaluated by their doctor before starting prenatal physical activity.

\section{Gestational hypertension}

As discussed in the Chronic hypertension section, regular physical activity is an important non-pharmaceutical therapy for blood pressure control, ${ }^{110}$ and as such, may also benefit women diagnosed with gestational hypertension.

Prenatal exercise appears to offer maternal and fetal health benefits, without increased risk of harm, in women with gestational hypertension. No adverse short-term or long-term maternal or fetal outcomes (maternal blood pressure, fetal heart rate, umbilical blood flow, birth weight) were observed following cycling exercise in women with gestational hypertension. ${ }^{5111}$ Additionally, a randomised controlled trial including hospitalised, high-risk pregnant women and women with gestational hypertension, demonstrated that muscle conditioning exercise did not cause any adverse changes in maternal blood pressure, uterine contractions or vaginal bleeding. ${ }^{63}$ Furthermore, prenatal exercise could positively impact overall cardiovascular risk profile during pregnancy (eg, insulin resistance and GWG) ${ }^{1597}$ which could stop the disease progressing to preeclampsia, although this requires further investigation.
Due to the potential of health benefits and low risk of adverse outcomes, women with gestational hypertension should engage with prenatal physical activity within recommended guidelines.

\section{Women who are categorised as obese}

Globally, the proportion of women categorised as overweight or obese has increased drastically over the past 30 years. ${ }^{112}$ Recent data from Canada show that $25 \%$ of women have obesity during pregnancy and $61 \%$ of women are categorised as overweight or obese. ${ }^{113}$ Obesity is associated with significantly greater odds of developing gestational diabetes mellitus, ${ }^{114}$ gestational hypertension, pre-eclampsia and macrosomia compared with women of a normal weight body mass index category ${ }^{115}$; however, prenatal physical activity may reduce these risks. A recent metaanalysis demonstrated that regular physical activity in women categorised as overweight or obese reduced the risk of preterm birth and gestational diabetes without any risk of adverse fetal outcomes such as low birth weight or stillbirth. ${ }^{116}$ In addition, no adverse outcomes of prenatal exercise have been reported in pregnant women with obesity. ${ }^{117}$ As such, women categorised as overweight or obese should complete regular prenatal physical activity.

Due to hormonally mediated increases in joint laxity as well as the biomechanical stress of gestation (eg, change in the centre of gravity, isolated anterior loading), all pregnant women are more likely to suffer from low back or pelvic girdle pain. ${ }^{118}$ The risk for musculoskeletal pain and injury in the back, hip, knee ankle and foot is higher in pregnant women categorised as overweight or obese due to chronic overloading of connective tissue structures. ${ }^{119}$ As such, light or non-weight bearing exercise, such as aquatic or cycling exercise, yoga or Pilates, should be recommended for pregnant women categorised as overweight or obese experiencing musculoskeletal pain. In the absence of musculoskeletal pain, weight-bearing exercise can be encouraged as previous exercise studies in this population have used walking interventions without reports of musculoskeletal injury or pain.

\section{Recurrent miscarriage and pregnancy loss}

Recurrent miscarriage, defined as the loss of three or more consecutive pregnancies before 24 weeks, affects $1 \%$ of women ${ }^{120}$ and may be attributed to genetic, structural, endocrine, immune, thrombophilic or 'unexplained' causes. Fear of miscarriage can be a barrier to prenatal exercise in early pregnancy ${ }^{121}$; however, a recent meta-analysis demonstrated no increased odds of miscarriage or perinatal mortality in otherwise healthy pregnant women who exercised compared with those who did not. ${ }^{18}$ It should be noted that this included spontaneous miscarriage data, and not specifically, recurrent pregnancy loss. Regardless, it remains unclear as to how exercise would negatively influence factors that lead to recurrent pregnancy loss. Fetal chromosomal defects, accounting for up to $60 \%$ of miscarriages, and maternal congenital uterine abnormalities, affecting up to $38 \%$ of women with recurrent miscarriage, ${ }^{120}$ are non-modifiable, and as such, would not be affected by prenatal exercise. ${ }^{122}$

There are no data specifically investigating the association between prenatal exercise and recurrent miscarriage; however, due to the underlying pathophysiology, it is unlikely that regular physical activity within guidelines would increase the risk of a loss in this population. Indeed, prenatal exercise may benefit factors that increase the risk of miscarriage, such as insulin resistance and obesity, ${ }^{123}$ as well as improve general maternal health. In consideration of the above, women with recurrent pregnancy loss should be encouraged to meet physical activity guidelines; 
however, it should be noted that these women may choose to avoid prenatal exercise due to fear of further miscarriage.

\section{Short cervix}

Previously, activity restriction was recommended for women with short cervix $(<25 \mathrm{~mm})$, but is now discouraged as no beneficial effect on pregnancy outcomes has been proven. In fact, preventing all physical activity increased the rate of preterm birth in women with a short cervix. ${ }^{124}$ Furthermore, exercising $>2$ days a week for $>20 \mathrm{~min}$ did not increase the risk of preterm birth in women with short cervix, but was associated with a nonsignificant reduction in delivery before 37 weeks (adjusted OR: $0.65,95 \%$ CI: 0.33 to 1.03 ). Additionally, physical activity was significantly lower in women at risk for preterm birth (including those with cervix $<20 \mathrm{~mm}$ ) who delivered before 37 weeks, compared with those who delivered at term. ${ }^{125}$ As such, there is a developing base of evidence demonstrating that physical activity has no adverse effect in women with short cervix and could even delay delivery. Women with short cervix should be advised to avoid high-impact and/or strenuous physical exercise as a precautionary measure, but in the absence of other complications, should be encouraged to meet current physical activity recommendations.

\section{Twin and high-order multiple pregnancies}

Multiple pregnancies face a significantly greater risk of maternal and infant morbidity and mortality as a result of preterm birth. ${ }^{126}$ Prenatal physical activity has many health benefits to women with singleton pregnancies, ${ }^{15-18} 91-939597$ and women with multiple pregnancies may experience similar benefits. However, current guidelines restrict twin pregnancies from prenatal exercise after 28 weeks' gestation and prevent all higher-order pregnancies from engaging with any MVPA.

Limited data support that women with twin pregnancies do not have adverse responses to prenatal exercise. Women with twin pregnancies have completed exercise interventions in observational studies with similar outcomes to women with singleton pregnancies (although this comparison was not the primary aim of these studies). ${ }^{127}$ Women with twin pregnancies $(n=26)$ were included in an assessment of physical activity in women at high risk of preterm birth. In this study, higher levels of light walking (measured in steps per day) were shown in women delivering at term compared with those delivering preterm, although this was not significant $(p=0.09)$, likely due to a lack of statistical power. ${ }^{125}$ The reports from these two studies, although limited, support that physical activity in twin pregnancy may reduce the risk of preterm delivery; however, well-controlled investigations into both acute responses and chronic outcomes following exercise in this population are needed to verify these findings.

Of note, in both of the studies presented, women with twin pregnancies were physically active beyond 28 weeks of gestation. ${ }^{125} 127-129$ This is highly important as $92 \%$ of obstetricians will recommend that women with twin pregnancies limit their exercise out of concern of preterm labour. ${ }^{130}$ In conflict with this practice, a recent Cochrane review showed that bed-rest had no beneficial effect on pregnancy outcomes (including preterm delivery) in twin pregnancies. ${ }^{19}$ Therefore, we believe that in the absence of other medical reasons where ambulation may be detrimental, light physical activity and activities of daily living should be maintained at minimum in twin pregnancies after 28 weeks. Women with uncomplicated twin pregnancies who wish to continue MVPA in the third trimester can do so, with acknowledgement that increased abdominal size, altered balance, higher fatigue and generalised aches and pains may limit their exercise levels.

At present, the effect of prenatal physical activity on higherorder multiple pregnancies is not known. There is no published data in this group, and this is likely due to the low incidence of women with high-order pregnancies, as well as their extreme risk of preterm birth. ${ }^{131}$ Furthermore, the anatomical (large extended abdomen) and physiological (excessive fatigue and musculoskeletal pain) constraints of higher-order pregnancies means that women are less likely to engage in prenatal exercise. However, all women with high-order pregnancies should be encouraged to maintain activities of daily living at minimum.

\section{Epilepsy}

Physical activity is increasingly viewed as a complementary therapy for patients with epilepsy. Specifically, regular exercise may improve epileptic seizure control via reduced epileptiform discharges following exercise ${ }^{132}$ and reduce associated comorbidities. ${ }^{133}$ Pregnant women with well-controlled epilepsy (those who are treated and stable with no recent history of seizures) should participate in MVPA according to current guidelines. In contrast, women with poorly controlled epilepsy (those who experience seizures despite treatment) may face some risk during exercise; however, this can be mitigated. Specifically, falling from tonic-clonic or atonic seizures and/or those that result in a transient loss of consciousness could result in traumatic injury to the fetus. Pregnant women with poorly controlled epilepsy should aim to achieve recommended physical activity guidelines but may need to individualise their intensity (eg, low to moderate), type (eg, weight-supported activities such as recumbent cycling) and location (eg, supervised gym, not exercising alone) of exercise to minimise the risk of harm to themselves and their fetus should they experience a seizure while exercising.

\section{Anaemia}

All women develop a degree of physiological anaemia in pregnancy due to haemodilution as a result of blood volume expansion. Haemoglobin levels $<100 \mathrm{~g} / \mathrm{L}$ may result in maternal symptoms, such as fatigue, and may be theorised to result in limitations in maternal oxygen carrying capacity during prenatal activity. However, there have been no negative maternal or fetal outcomes associated with anaemia and MVPA. ${ }^{134}$

At present, there is limited supporting or theoretical evidence to uphold anaemia as a contraindication to exercise in pregnancy. Women with a haemoglobin level $<100 \mathrm{~g} / \mathrm{L}$ should receive oral iron supplements to elevate haemoglobin levels and mitigate the symptoms associated with anaemia. If asymptomatic, women should maintain MVPA. If women are symptomatic, they may consider reducing the intensity of prenatal exercise, but should remain physically active.

\section{CONCLUSIONS}

Since 1985, there has been a critical shift in recommendations regarding prenatal exercise, from a potentially harmful behaviour to a critical prescription to improve maternal and fetal health. We have identified 11 conditions (chronic or gestational hypertension, overweight/obesity, recurrent miscarriage, short cervix, multiple pregnancies, epilepsy and anaemia, orthopaedic limitations, history of extremely sedentary lifestyle, history of spontaneous preterm labour or fetal growth restriction) where there is absolutely no evidence to support stopping prenatal exercise, in fact, becoming completely inactive could result in increased risk of adverse pregnancy outcomes. There 


\section{What is already known}

- Prenatal exercise guidelines include a list of medical reasons (contraindications) where a reduction or cessation of exercise is recommended.

- Contraindications are inconsistent among guidelines.

- Many of the contraindications are based on expert opinion or limited empirical evidence.

\section{What are the new findings}

- We systematically reviewed and synthesised available literature regarding prenatal exercise in women with contraindications.

- We identified ten conditions where engaging in regular moderate-vigorous physical activity has a strong potential for adverse effects for the mother and/or fetus (absolute contraindications).

- We identified ten disorders where we recommend modification of activities (reduction in intensity, duration or volume; exercise adaptation) be considered over complete cessation of activity (relative contraindications).

are some conditions (mild respiratory disorders, acquired or congenital HD with exercise tolerance, mild pre-eclampsia, wellcontrolled type 1 diabetes, PPROMs, placenta previa after 28 weeks, untreated thyroid disease, severe and symptomatic eating disorders, undernutrition, heavy smoking in the presence of comorbidities) where regular physical activity is likely safe, but the exercise prescription may need to be modified and women would benefit from additional monitoring or support from their healthcare professional. Finally, we remain supportive of more serious disorders (severe respiratory disorders, severe acquired or congenital HD with exercise intolerance, placental abruption, vasa previa, uncontrolled type 1 diabetes, IUGR, active preterm labour, severe pre-eclampsia and cervical insufficiency) as reasons to avoid MVPA during pregnancy. However, pregnant women with these conditions should maintain activities of daily living where possible, as per evidence showing the adverse effects of complete bed-rest in pregnancy.

We sought to provide evidence-based classifications of absolute and relative contraindications to prenatal exercise; however, in many cases, previous research was extremely limited. We therefore present a call for future research to include women with medical disorders that have previously been considered contraindications to prenatal exercise. Building on the current lack of data in these women will allow better information for both pregnant women and their obstetric healthcare providers regarding prenatal physical activity.

Twitter Victoria L Meah @vtorixm and Margie H Davenport @ExercisePreg

Acknowledgements The authors acknowledge Dr Allison Sivak, University of Alberta for her assistance in building the search strategy for this systematic review.

Contributors MHD, GAD, VLM developed the concept; VLM wrote the first draft of the manuscript; all authors revised and reviewed the final manuscript.

Funding VLM is funded by generous supporters of the Lois Hole Hospital for Women through the Women and Children's Health Research Institute Postdoctoral Fellowship. MHD is funded by Heart and Stroke Foundation Canada Joint National and Alberta Improving Hearth Health for Women New Investigator award (HSFC NNIA Davenport).

Competing interests None declared.

\section{Patient consent for publication Not required.}

Ethics approval Ethical approval for this study was not required. The data retrieved for the systematic review is publicly available information that is legally accessible.

Provenance and peer review Not commissioned; externally peer reviewed.

Data availability statement All data relevant to the study are included in the article or uploaded as supplementary information.

\section{ORCID iDs}

Victoria L Meah http://orcid.org/0000-0003-3312-4010

Margie H Davenport http://orcid.org/0000-0001-5627-5773

\section{REFERENCES}

1 Mottola MF, Davenport MH, Ruchat S-M, et al. No. 367-2019 Canadian guideline for physical activity throughout pregnancy. J Obstet Gynaecol Can 2018;40:1528-37.

2 Mottola MF, Davenport MH, Ruchat S-M, et al. N 367-2019 Lignes Directrices Canadiennes SUR L'activité physique Durant La Grossesse. J Obstet Gynaecol Can 2018;40:1538-48.

3 Mottola MF, Davenport MH, Ruchat S-M, et al. 2019 Canadian guideline for physical activity throughout pregnancy. Br J Sports Med 2018;52:1339-46.

4 Department of Health \& Social Care. Uk chief medical officers' physical activity guidelines, 2019. Available: https://assets.publishing.service.gov.uk/government/ uploads/system/uploads/attachment_data/file/832868/ukchief-medical-officersphysical-activity-guidelines.pdf [Accessed 6 Mar 2020].

5 Sports Medicine Australia. Sma statement: the benefits and risks of exercise during pregnancy, 2009. Available: https://pubmed.ncbi.nlm.nih.gov/12054382/

6 American College of Obstetricians and Gynecologists. ACOG Committee opinion no. 650: physical activity and exercise during pregnancy and the postpartum period. Obstet Gynecol 2015;126:e135-42.

7 Bo K, Artal R, Barakat R, et al. Exercise and pregnancy in recreational and elite athletes: 2016/2017 evidence summary from the IOC expert group meeting, Lausanne. Part 5. recommendations for health professionals and active women. $\mathrm{Br} J$ Sports Med 2018;52:1080-5.

8 Royal Australian and New Zealand College of Obstetricians and Gynaecologists. Exercise during pregnancy (C-Obs 62), 2016. Available: https://www.ranzcog.edu. au/RANZCOG_SITE/media/RANZCOG-MEDIA/Women $\% 27 s \% 20 \mathrm{Health} /$ Statement $\%$ 20and\%20guidelines/Clinical-Obstetrics/Exercise-during-pregnancy-(C-Obs-62)New-July-2016.pdf?ext=.pdf

9 Damm P, Klemmensen AK, Clausen TD, et al. Physical activity and pregnancy [Motion og graviditet], 2008. Available: http://clin.au.dk/fileadmin/www.ki.au. dk/forskning/forskningsenheder/gyn__kologisk-obstetrisk_afd__y/logistics/ sandbjerg_m__der/sandbjerg_2008/motionoggraviditet.pdf [Accessed 6 Apr 2020].

10 Haute Autorité de Santé. Comment meiux informer les femmes enceintes? Recommandations pour les professionnels de santé. Siant-Denis La Plaine 2005.

11 Miyake HK, Nakai A. The Guideline for safety sports during pregnancy. J Jpn Clin Sports Med 2010;18:216-8.

12 Strømme S, Anderssen S, Hjermann I, et al. Physical Activity and Health-Guidelines [Fysisk aktivitet og helse - Anbefalinger]. The Directorate of Health and Social Affairs 2000.

13 Gurpegui M. Ejercicio fisico y deporte durante el embarazo. In: Gonzalez E, ed. Manual de Asistencia al Embarazo normal. 2nd Ed. Zaragoza, Spain: Seccion de Medicina Perinatal de la Sociedad Española de Ginecologia y Obstetricia, 2001: 357-71.

14 US Department of Health and Human Services. 2018 physical activity guidelines Advisory Committee scientific report. Washington, DC, 2018.

15 Davenport MH, Ruchat S-M, Poitras VJ, et al. Prenatal exercise for the prevention of gestational diabetes mellitus and hypertensive disorders of pregnancy: a systematic review and meta-analysis. Br J Sports Med 2018;52:1367-75.

16 Davenport MH, McCurdy AP, Mottola MF, et al. Impact of prenatal exercise on both prenatal and postnatal anxiety and depressive symptoms: a systematic review and meta-analysis. Br J Sports Med 2018;52:1376-85.

17 Davenport MH, Meah VL, Ruchat S-M, et al. Impact of prenatal exercise on neonatal and childhood outcomes: a systematic review and meta-analysis. Br J Sports Med 2018;52:1386-96.

18 Davenport MH, Kathol AJ, Mottola MF, et al. Prenatal exercise is not associated with fetal mortality: a systematic review and meta-analysis. Br J Sports Med 2019;53:108-15.

19 da Silva Lopes K, Takemoto Y, Ota E, et al. Bed rest with and without hospitalisation in multiple pregnancy for improving perinatal outcomes. Cochrane Database Syst Rev 2017;3:CD012031.

20 Sosa CG, Althabe F, Belizan JM, et al. Bed rest in singleton pregnancies for preventing preterm birth. Cochrane Database Syst Rev 2015;3:CD003581.

21 Matenchuk B, Khurana R, Cai C, et al. Prenatal bed rest in developed and developing regions: a systematic review and meta-analysis. CMAJ Open 2019;7:E435-45. 
22 Sprague AE, O'Brien B, Newburn-Cook C, et al. Bed rest and activity restriction for women at risk for preterm birth: a survey of Canadian prenatal care providers. J Obstet Gynaecol Can 2008;30:317-26.

23 Fox NS, Gelber SE, Kalish RB, et al. The recommendation for bed rest in the setting of arrested preterm labor and premature rupture of membranes. Am J Obstet Gynecol 2009;200:165.e1-165.e6.

24 Moher D, Shamseer L, Clarke M, et al. Preferred reporting items for systematic review and meta-analysis protocols (PRISMA-P) 2015 statement. Syst Rev 2015;4:1

25 Boggess KA, Easterling TR, Raghu G. Management and outcome of pregnant women with interstitial and restrictive lung disease. Am J Obstet Gynecol 1995;173:1007-14

26 Patel EM, Swamy GK, Heine RP, et al. Medical and obstetric complications among pregnant women with cystic fibrosis. Am J Obstet Gynecol 2015;212:98.e1-98.e9.

27 lakovleva EB, Generalov SI, Seredenko LP. The effect of graded physical loading on the adaptive-compensatory potentials in a high-risk group of pregnant women. Voprosy kurortologii, fizioterapii, i lechebnoi fizicheskoi kultury 1990;5:31-3.

28 Dolgin M, Fox A, Gorlin R, et al. Nomenclature and criteria for diagnosis of diseases of the heart and great vessels. 9th ed. Boston; London: Little Brown \& Co, 1994.

29 Longmuir PE, Brothers JA, de Ferranti SD, et al. Promotion of physical activity for children and adults with congenital heart disease: a scientific statement from the American heart association. Circulation 2013;127:2147-59.

30 Robbe H. Physical working capacity, blood volume and heart volume in cardiac patients during and after pregnancy. Acta Obstet Gynecol Scand 1959;38:1-61.

31 Ueland K, Novy MJ, Metcalfe J. Hemodynamic responses of patients with heart disease to pregnancy and exercise. Am J Obstet Gynecol 1972;113:47-59.

32 Houser L, Zaragoza-Macias E, Jones TK, et al. Transcatheter closure of atrial septal communication during pregnancy in women with Ebstein's anomaly of the tricuspid valve and cyanosis. Catheterization and Cardiovascular Interventions 2015:85:842-6.

33 Lui GK, Silversides CK, Khairy P, et al. Heart rate response during exercise and pregnancy outcome in women with congenital heart disease. Circulation 2011;123:242-8.

34 Ohuchi $\mathrm{H}$, Tanabe $\mathrm{Y}$, Kamiya $\mathrm{C}$, et al. Cardiopulmonary variables during exercise predict pregnancy outcome in women with congenital heart disease. Circ $J$ 2013;77:470-6.

35 American College of Obstetricians and Gynecologists. ACOG practice Bulletin No. 212: pregnancy and heart disease. Obstet Gynecol 2019;133:e320-56.

36 Regitz-Zagrosek V, Blomstrom Lundqvist C, Borghi C, et al. ESC guidelines on the management of cardiovascular diseases during pregnancy: the task force on the management of cardiovascular diseases during pregnancy of the European Society of Cardiology (ESC). Eur Heart J 2011;32:3147-97.

37 Heidbüchel H, Corrado D, Biffi A, et al. Recommendations for participation in leisure-time physical activity and competitive sports of patients with arrhythmias and potentially arrhythmogenic conditions. Part II: ventricular arrhythmias, channelopathies and implantable defibrillators. Eur J Cardiovasc Prev Rehabil 2006;13:676-86

38 Heidbüchel $H$, Corrado D, Biffi $A$, et al. Recommendations for participation in leisure-time physical activity and competitive sports of patients with arrhythmias and potentially arrhythmogenic conditions. Part II: ventricular arrhythmias, channelopathies and implantable defibrillators. Eur J Cardiovasc Prev Rehabil 2006:13:676-86.

39 Tikkanen M. Placental abruption: epidemiology, risk factors and consequences. Acta Obstet Gynecol Scand 2011;90:140-9.

40 Downes KL, Grantz KL, Shenassa ED. Maternal, labor, delivery, and perinatal outcomes associated with placental abruption: a systematic review. Am J Perinatol 2017:34:935-57.

41 Chahal HS, Gelaye B, Mostofsky E, et al. Physical exertion immediately prior to placental abruption: a case-crossover study. Am J Epidemiol 2018;187:2073-9.

42 Baylin A, Guyer H. Invited commentary: physical exertion and placental AbruptionPublic health implications and future directions. Am J Epidemio/ 2018;187:2080-2.

43 Sinkey RG, Odibo AO, Dashe JS. \#37: Diagnosis and management of vasa previa. Am J Obstet Gynecol 2015;213:615-9.

44 Sakornbut E, Leeman L, Fontaine P. Late pregnancy bleeding. Am Fam Physician 2007;75:1199-206

45 Jensen DM, Damm P, Moelsted-Pedersen L, et al. Outcomes in type 1 diabetic pregnancies: a nationwide, population-based study. Diabetes Care 2004;27:2819-23.

46 Canadian Diabetes Association Clinical Practice Guidelines Expert Committee. Clinical practice guidelines for the prevention and management of diabetes in Canada. Can J Diabetes 2018;2018:S1-325.

47 Hollingsworth DR, Moore TR. Postprandial walking exercise in pregnant insulin-dependent (type I) diabetic women: reduction of plasma lipid levels but absence of a significant effect on glycemic control. Am J Obstet Gynecol 1987;157:1359-63.

48 Kumareswaran K, Elleri D, Allen JM, et al. Physical activity energy expenditure and glucose control in pregnant women with type 1 diabetes: is 30 minutes of daily exercise enough? Diabetes Care 2013;36:1095-101.
49 Laurin J, Persson P-H. The effect of bedrest in hospital on fetal outcome in pregnancies complicated by intra-uterine growth retardation. Acta Obstet Gynecol Scand 1987;66:407-11.

50 Rafla NM. The effect of maternal exercise on umbilical artery velocimetry waveforms in intrauterine growth retardation. J Obstet Gynaecol 1999;19:469-73.

51 Rafla NM, Cook JR. The effect of maternal exercise on fetal heart rate. Journal of Obstetrics and Gynaecology 1999;19:381-4.

52 Nabeshima Y, Sasaki J, Mesaki N, et al. Effect of maternal exercise on fetal umbilical artery waveforms: the comparison of IUGR and AFD fetuses. J Obstet Gynaecol Res 1997:23:255-9

53 Ertan AK, Schanz S, Tanriverdi HA, et al. Doppler examinations of fetal and uteroplacental blood flow in AGA and IUGR fetuses before and after maternal physical exercise with the bicycle ergometer. J Perinat Med 2004;32:260-5.

54 Chaddha V, Simchen MJ, Hornberger LK, et al. Fetal response to maternal exercise in pregnancies with uteroplacental insufficiency. Am J Obstet Gynecol 2005; 193:995-9.

55 Goldenberg RL, Culhane JF, lams JD, et al. Epidemiology and causes of preterm birth. Lancet 2008;371:75-84.

56 Cooper KA, Hunyor SN, Boyce ES, et al. Fetal heart race and maternal cardiovascular and catecholamine responses to dynamic exercise. Aust N Z J Obstet Gynaecol 1987:27:220-3

57 Artal R, Platt LD, Sperling M, et al. I. maternal cardiovascular and metabolic responses in normal pregnancy. Am J Obstet Gynecol 1981;140:123-7.

58 Rauramo I, Andersson B, Laatikainen T, et al. Stress hormones and placental steroids in physical exercise during pregnancy. BJOG:An international journal of O\&G 1982:89:921-5.

59 Brown MA, Magee LA, Kenny LC, et al. Hypertensive disorders of pregnancy: ISSHP classification, diagnosis, and management recommendations for international practice. Hypertension 2018;72:24-43.

60 Steegers EAP, von Dadelszen P, Duvekot JJ, et al. Pre-Eclampsia. The Lancet $2010 \cdot 376: 631-44$

61 Chen K-H, Seow K-M, Chen L-R. Progression of gestational hypertension to pre-eclampsia: a cohort study of 20,103 pregnancies. Pregnancy Hypertens 2017; 10:230-7

62 Magee LA, Pels A, Helewa M, et al. Diagnosis, evaluation, and management of the hypertensive disorders of pregnancy: Executive summary. Journal of Obstetrics and Gynaecology Canada 2014;36:416-38.

63 Brun CR, Shoemaker JK, Bocking A, et al. Bed-Rest exercise, activity restriction, and high-risk pregnancies: a feasibility study. Appl Physiol Nutr Metab 2011;36:577-82

64 Rauramo I, Forss M. Effect of exercise on placental blood flow in pregnancies complicated by hypertension, diabetes or intrahepatic cholestasis. Acta Obstet Gynecol Scand 1988:67:15-20.

65 Rauramo I. Effect of short-term physical exercise on foetal heart rate and uterine activity in normal and abnormal pregnancies. Ann Chir Gynaecol 1987;76:274-9.

66 Morris N, Osborn SB, Payling Wright $\mathrm{H}$, et al. Effective uterine bloodflow during exercise in normal and pre-eclamptic pregnancies. Lancet 1956;271:481-4.

67 Roman A, Suhag A, Berghella V. Overview of cervical insufficiency: diagnosis, etiologies, and risk factors. Clin Obstet Gynecol 2016;59:237-40.

68 Bigelow CA, Factor SH, Miller M, et al. Pilot randomized controlled trial to evaluate the impact of bed rest on maternal and fetal outcomes in women with preterm premature rupture of the membranes. Am J Perinatol 2016:33:356-63.

69 Tsakiridis I, Mamopoulos A, Chalkia-Prapa E-M, et al. Preterm premature rupture of membranes: a review of 3 national guidelines. Obstet Gynecol Surv 2018:73:368-75

70 Roman A, Watters N, Moses D, et al. 690: maternal activity level in patients with preterm premature rupture of membranes: a prospective observational cohort study. Am J Obstet Gynecol 2018;218:S414-5.

71 Mustafá SA, Brizot ML, Carvalho MHB, et al. Transvaginal ultrasonography in predicting placenta previa at delivery: a longitudinal study. Ultrasound Obstet Gynecol 2002;20:356-9.

72 Sheiner E, Shoham-Vardi I, Hallak M, et al. Placenta previa: obstetric risk factors and pregnancy outcome. J Matern Fetal Med 2001;10:414-9.

73 Maor E, Kivity S, Kopel E, et al. Differences in heart rate profile during exercise among subjects with subclinical thyroid disease. Thyroid 2013;23:1226-32.

74 Almas SP, Werneck FZ, Coelho EF, et al. Heart rate kinetics during exercise in patients with subclinical hypothyroidism. J App/ Physiol 2017;122:893-8.

75 Barona M, Taborelli E, Corfield F, et al. Neurobehavioural and cognitive development in infants born to mothers with eating disorders. J Child Psychol Psychiatr 2017:58:931-8.

76 Micali N, Stemann Larsen P, Strandberg-Larsen K, et al. Size at birth and preterm birth in women with lifetime eating disorders: a prospective population-based study. BJOG: Int J Obstet Gy 2016;123:1301-10.

77 Eagles JM, Lee AJ, Raja EA, et al. Pregnancy outcomes of women with and without a history of anorexia nervosa. Psychol Med 2012;42:2651-60.

78 Madsen IR, Hørder K, Støving RK. Remission of eating disorder during pregnancy: five cases and brief clinical review. Journal of Psychosomatic Obstetrics \& Gynecology 2009;30:122-6. 
79 Hollifield J, Hobdy J. The course of pregnancy complicated by Bulimia. Psychotherapy: Theory, Research, Practice, Training 1990;27:249-55.

80 Triunfo S, Lanzone A. Impact of maternal under nutrition on obstetric outcomes. $J$ Endocrinol Invest 2015;38:31-8.

81 Papoz L, Eschwege E, Pequignot G, et al. Maternal smoking and birth weight in relation to dietary habits. Am J Obstet Gynecol 1982;142:870-6.

82 Bernstein IM, Mongeon JA, Badger GJ, et al. Maternal smoking and its association with birth weight. Obstetrics \& Gynecology 2005;106:986-91.

83 Bureau MA, Shapcott D, Berthiaume Y, et al. Maternal cigarette smoking and fetal oxygen transport: a study of p50, 2,3-diphosphoglycerate, total hemoglobin, hematocrit, and type F hemoglobin in fetal blood. Pediatrics 1983;72:22-6.

84 Morrow RJ, Ritchie JWK, Bull SB. Maternal cigarette smoking: the effects on umbilical and uterine blood flow velocity. Am J Obstet Gynecol 1988;159:1069-71.

85 Socol ML, Manning FA, Murata Y, et al. Maternal smoking causes fetal hypoxia: experimental evidence. Am J Obstet Gynecol 1982;142:214-8.

86 Marufu TC, Ahankari A, Coleman T, et al. Maternal smoking and the risk of still birth: systematic review and meta-analysis. BMC Public Health 2015;15:239.

87 Rayfield S, Plugge E. Systematic review and meta-analysis of the association between maternal smoking in pregnancy and childhood overweight and obesity. J Epidemiol Community Health 2017;71:162-73.

88 Weissgerber TL, Davies GAL, Roberts JM. Modification of angiogenic factors by regular and acute exercise during pregnancy. J App/ Physiol 2010;108:1217-23.

89 Ramírez-Vélez R, Bustamante J, Czerniczyniec A, et al. Effect of exercise training on eNOS expression, NO production and oxygen metabolism in human placenta. PLOS One 2013;8:e80225.

90 Morales-Suárez-Varela M, Nohr EA, Bech BH, et al. Smoking, physical exercise, BMI and late foetal death: a study within the Danish national birth cohort. Eur J Epidemio/ 2016:31:999-1009.

91 Davenport MH, Marchand A-A, Mottola MF, et al. Exercise for the prevention and treatment of low back, pelvic girdle and lumbopelvic pain during pregnancy: a systematic review and meta-analysis. Br J Sports Med 2019;53:90-8.

92 Davenport MH, Nagpal TS, Mottola MF, et al. Prenatal exercise (including but not limited to pelvic floor muscle training) and urinary incontinence during and following pregnancy: a systematic review and meta-analysis. Br J Sports Med 2018:52:1397-404

93 Davenport MH, Ruchat S-M, Sobierajski F, et al. Impact of prenatal exercise on maternal harms, labour and delivery outcomes: a systematic review and metaanalysis. Br J Sports Med 2019;53:99-107.

94 Davenport MH, Sobierajski F, Mottola MF, et al. Glucose responses to acute and chronic exercise during pregnancy: a systematic review and meta-analysis. $\mathrm{Br} \mathrm{J}$ Sports Med 2018;52:1357-66.

95 Davenport MH, Yoo C, Mottola MF, et al. Effects of prenatal exercise on incidence of congenital anomalies and hyperthermia: a systematic review and meta-analysis. $\mathrm{Br} J$ Sports Med 2019;53:116-23.

96 Mottola MF, Nagpal TS, Bgeginski R, et al. Is supine exercise associated with adverse maternal and fetal outcomes? A systematic review. Br J Sports Med 2019:53:82-9.

97 Ruchat S-M, Mottola MF, Skow RJ, et al. Effectiveness of exercise interventions in the prevention of excessive gestational weight gain and postpartum weight retention: a systematic review and meta-analysis. Br J Sports Med 2018:52:1347-56

98 Skow RJ, Davenport MH, Mottola MF, et al. Effects of prenatal exercise on fetal heart rate, umbilical and uterine blood flow: a systematic review and meta-analysis. $\mathrm{Br}$ Sports Med 2019:53:124-33.

99 Davenport MH, Ruchat S-M, Mottola MF, et al. 2019 Canadian guideline for physical activity throughout pregnancy: methodology. J Obstet Gynaecol Can 2018;40:1468-83.

100 Eijsvogels TM, Molossi S, Lee DC, et al. Exercise at the extremes: the amount of exercise to reduce cardiovascular events. J Am Coll Cardiol 2016;67:316-29.

101 Seely EW, Ecker J. Chronic hypertension in pregnancy. Circulation 2014;129:1254-61.

102 Catov JM, Nohr EA, Olsen J, et al. Chronic hypertension related to risk for preterm and term small for gestational age births. Obstetrics \& Gynecology 2008;112:290-6.

103 Ananth CV, Peltier MR, Kinzler WL, et al. Chronic hypertension and risk of placental abruption: is the association modified by ischemic placental disease? Am J Obstet Gynecol 2007; 197:273.e1-273.e7.

104 Bateman BT, Huybrechts KF, Fischer MA, et al. Chronic hypertension in pregnancy and the risk of congenital malformations: a cohort study. Am J Obstet Gynecol 2015:212:337.e1-337.e14.

105 Abalos E, Duley L, Steyn DW. Antihypertensive drug therapy for mild to moderate hypertension during pregnancy. Cochrane Database Syst Rev 2014:2:CD002252.

106 MacDonald JR. Potential causes, mechanisms, and implications of post exercise hypotension. J Hum Hypertens 2002;16:225-36.
107 MacDonald JR, MacDougall JD, Hogben CD. The effects of exercise duration on postexercise hypotension. J Hum Hypertens 2000;14:125-9.

108 Szymanski LM, Satin AJ. 331: maternal and fetal responses to moderateintensity exercise in women with chronic hypertension. Am J Obstet Gynecol 2019;220:\$230-1.

109 Adesegun D, Cai C, Sivak A, et al. Prenatal exercise and Pre-gestational diseases: a systematic review and meta-analysis. Journal of Obstetrics and Gynaecology Canada 2019:41:1134-43.

110 Sharman JE, La Gerche A, Coombes JS. Exercise and cardiovascular risk in patients with hypertension. Am J Hypertens 2015;28:147-58.

111 Rafla NM. The effect of maternal exercise on umbilical artery blood flow in pregnancy-induced hypertension. J Obstet Gynaecol 2000;20:19-23.

$112 \mathrm{Ng} \mathrm{M}$, Fleming T, Robinson M, et al. Global, regional, and national prevalence of overweight and obesity in children and adults during 1980-2013: a systematic analysis for the global burden of disease study 2013. Lancet 2014:384:766-81.

113 Canadian Health Measures Survey. Cycle 1 data tables: introduction. Ottawa, ON, 2010.

114 Chu SY, Callaghan WM, Kim SY, et al. Maternal obesity and risk of gestational diabetes mellitus. Diabetes Care 2007:30:2070-6.

115 Weiss JL, Malone FD, Emig D, et al. Obesity, obstetric complications and cesarean delivery rate--a population-based screening study. Am J Obstet Gynecol 2004:190:1091-7.

116 Magro-Malosso ER, Saccone G, Di Mascio D, et al. Exercise during pregnancy and risk of preterm birth in overweight and obese women: a systematic review and meta-analysis of randomized controlled trials. Acta Obstet Gynecol Scand 2017:96:263-73.

117 Langer 0 . Prevention of obesity and diabetes in pregnancy: is it an impossible dream? Am J Obstet Gynecol 2018:218:581-9.

118 Wu WH, Meijer OG, Uegaki K, et al. Pregnancy-Related pelvic girdle pain (ppp), I: terminology, clinical presentation, and prevalence. Eur Spine J 2004;13:575-89.

119 Wearing SC, Hennig EM, Byrne NM, et al. Musculoskeletal disorders associated with obesity: a biomechanical perspective. Obes Rev 2006;7:239-50.

120 Rai R, Regan L. Recurrent miscarriage. Lancet 2006;368:601-11.

121 Hegaard HK, Kjaergaard H, Damm PP, et al. Experiences of physical activity during pregnancy in Danish nulliparous women with a physically active life before pregnancy. A qualitative study. BMC Pregnancy Childbirth 2010;10:33.

122 Latka M, Kline J, Hatch M. Exercise and spontaneous abortion of known karyotype. Epidemiology 1999;10:73-5

123 Feodor Nilsson S, Andersen PK, Strandberg-Larsen K, et al. Risk factors for miscarriage from a prevention perspective: a nationwide follow-up study. BJOG 2014;121:1375-84

124 Grobman WA, Gilbert SA, lams JD, et al. Activity restriction among women with a short cervix. Obstet Gynecol 2013;121:1181-6.

125 Zemet R, Schiff E, Manovitch Z, et al. Quantitative assessment of physical activity in pregnant women with sonographic short cervix and the risk for preterm delivery: a prospective pilot study. PLoS One 2018;13:e0198949.

126 Norwitz ER, Edusa V, Park JS. Maternal physiology and complications of multiple pregnancy. Semin Perinatol 2005:29:338-48.

127 Sechrist DM, Tiongco CG, Whisner SM, et al. Physiological effects of aquatic exercise in pregnant women on bed rest. Occup Ther Health Care 2015:29:330-9.

128 Bailey DM, Davies B, Budgett $\mathrm{R}$, et al. Endurance training during a twin pregnancy in a marathon runner. Lancet 1998;351:1182.

129 Davies B, Bailey DM, Budgett $\mathrm{R}$, et al. Intensive training during a twin pregnancy. A case report. Int J Sports Med 1999;20:415-8.

130 Maloni JA, Cohen AW, Kane JH. Prescription of activity restriction to treat high-risk pregnancies. J Womens Health 1998;7:351-8.

131 Wen SW, Demissie K, Yang Q, et al. Maternal morbidity and obstetric complications in triplet pregnancies and quadruplet and higher-order multiple pregnancies. Am J Obstet Gynecol 2004:191:254-8.

132 Arida RM, de Almeida A-CG, Cavalheiro EA, et al. Experimental and clinical findings from physical exercise as complementary therapy for epilepsy. Epilepsy Behav 2013:26:273-8

133 Pimentel J, Tojal R, Morgado J. Epilepsy and physical exercise. Seizure 2015:25:87-94.

134 Barakat R, Ruiz JR, Lucia A. Exercise during pregnancy and risk of maternal anaemia: a randomised controlled trial. Br J Sports Med 2009:43:954-6.

135 Evenson KR, Barakat R, Brown WJ, et al. Guidelines for physical activity during pregnancy: comparisons from around the world. Am J Lifestyle Med 2014:8:102-21.

136 Physical activity in pregnancy infographic guidance, 2017. Available: https://assets. publishing.service.gov.uk/government/uploads/system/uploads/attachment data/ file/831430/Withdrawn_Physical_activity_pregnancy_infographic_guidance.pdf [Accessed March 9 2020]. 